\title{
OMEPRAZOLE COMPARED WITH MISOPROSTOL FOR ULCERS ASSOCIATED WITH NONSTEROIDAL ANTIINFLAMMATORY DRUGS
}

\author{
Christopher J. Hawkey, D.M., Jeffrey A. Karrasch, M.B., B.S., Leszek Szczepañski, Ph.D., \\ Donald G. Walker, M.B., B.S., Alan Barkun, M.D., C.M., Anthony J. Swannell, M.B., \\ and NeVILle D. Yeomans, M.D., \\ for the OMeprazole versus Misoprostol for NSAID-Induced Ulcer Management (OMNIUM) Study Group*
}

\begin{abstract}
Background Misoprostol is effective for ulcers associated with the use of nonsteroidal antiinflammatory drugs (NSAIDs) but is often poorly tolerated because of diarrhea and abdominal pain. We compared the efficacy of omeprazole and misoprostol in healing and preventing ulcers associated with NSAIDs.
\end{abstract}

Methods In a double-blind study, we randomly assigned 935 patients who required continuous NSAID therapy and who had ulcers or more than 10 erosions in the stomach or duodenum (or both) to receive $20 \mathrm{mg}$ or $40 \mathrm{mg}$ of omeprazole orally in the morning or $200 \mu \mathrm{g}$ of misoprostol orally four times daily. Patients were treated for four weeks or, in the absence of healing, eight weeks. Treatment success was defined as the absence of ulcers and the presence of fewer than five erosions at each site and not more than mild dyspepsia. We then randomly reassigned 732 patients in whom treatment was successful to maintenance therapy with $20 \mathrm{mg}$ of omeprazole daily, $200 \mu \mathrm{g}$ of misoprostol twice daily, or placebo for six months.

Results At eight weeks, treatment was successful in 76 percent of the patients given $20 \mathrm{mg}$ of omeprazole (233 of 308), 75 percent of those given $40 \mathrm{mg}$ of omeprazole (237 of 315 ), and 71 percent of those given misoprostol (212 of 298). The rates of gastriculcer healing were significantly higher with $20 \mathrm{mg}$ of omeprazole (but not $40 \mathrm{mg}$ of omeprazole) than with misoprostol. Healing rates among patients with duodenal ulcers were higher with either dose of omeprazole than with misoprostol, whereas healing rates among patients with erosions alone were higher with misoprostol. More patients remained in remission during maintenance treatment with omeprazole (61 percent) than with misoprostol (48 percent, $P=0.001)$ and with either drug than with placebo (27 percent, $\mathrm{P}<0.001)$. There were more adverse events during the healing phase in the misoprostol group than in the groups given $20 \mathrm{mg}$ and $40 \mathrm{mg}$ of omeprazole (59 percent, 48 percent, and 46 percent, respectively).

Conclusions The overall rates of successful treatment of ulcers, erosions, and symptoms associated with NSAIDs were similar for the two doses of omeprazole and misoprostol. Maintenance therapy with omeprazole was associated with a lower rate of relapse than misoprostol. Omeprazole was better tolerated than misoprostol. (N Engl J Med 1998;338: 727-34.)

(c)1998, Massachusetts Medical Society.

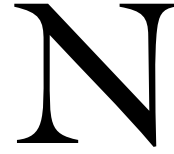

ONSTEROIDAL antiinflammatory drugs (NSAIDs) are widely used ${ }^{1,2}$ but have substantial gastroduodenal toxicity and account for 21 to 25 percent of reported adverse reactions in patients taking these drugs in combination with other medications. ${ }^{3,4}$ Epidemiologic studies have estimated that the risks of gastropathy and death are 3 to 10 times as high ${ }^{5-10}$ among patients who take NSAIDs regularly as among those who do not, and endoscopic studies have shown that the prevalence of peptic ulcers is 20 to 30 percent among regular users of NSAIDs. ${ }^{11}$

Hitherto, the most effective approach to ulcer prophylaxis has used misoprostol to replace the cytoprotective prostaglandins that NSAIDs deplete from the gastroduodenal mucosa. ${ }^{12-15}$ However, misoprostol is often poorly tolerated because of diarrhea and abdominal pain. An alternative approach is to protect the gastroduodenal mucosa by suppressing acid secretion. Acid has an important permissive role in NSAID-associated mucosal injury. ${ }^{16}$ Most NSAIDs are weak acids ${ }^{17}$ that selectively concentrate in the mucosa at low intragastric $\mathrm{pH}$, enhancing the diffusion of acid from the lumen to the mucosa and potentiating mucosal injury. ${ }^{18-21}$ Elevation of the intragastric $\mathrm{pH}$ to 4 or higher with omeprazole markedly reduces acute NSAID-associated mucosal injury. ${ }^{22,23}$ The profound acid suppression induced by proton-pump inhibitors may represent a mechanism by which the slowing of ulcer healing associated with concurrent use of NSAIDs and histamine $\mathrm{H}_{2}$ receptor antagonists can be overcome. ${ }^{24,25} \mathrm{We}$ compared an antisecretory strategy using omeprazole with a cytoprotective strategy using misoprostol in patients taking long-term NSAIDs.

From the Division of Gastroenterology, University Hospital, Nottingham, United Kingdom (C.J.H.); the Peninsula Specialist Centre, Kippa Ring, Australia (J.A.K.); the Department of Rheumatology, University Medical School, Lublin, Poland (L.S.); Sunshine Coast Day Surgery, Maroochydore, Australia (D.G.W.); the Division of Gastroenterology, Montreal General Hospital, Montreal (A.B.); the Rheumatology Unit, City Hospital, Nottingham, United Kingdom (A.J.S.); and the Department of Medicine, University of Melbourne, Western Hospital, Melbourne, Australia (N.D.Y.). Address reprint requests to Dr. Hawkey at the Nottingham Gastrointestinal Trials Service, Division of Gastroenterology, University Hospital, Nottingham NG7 2UH, United Kingdom.

*Other participants in the OMNIUM Study are listed in the Appendix. 


\section{METHODS}

\section{Study Design and Recruitment}

The study was an international, double-blind, randomized comparison of the efficacy, tolerability, and safety of omeprazole and misoprostol as healing or maintenance treatments for patients receiving long-term treatment with NSAIDs. The study was approved by the ethics committees of the participating centers and conducted in 14 countries (93 centers) from April 1992 to April 1995 in accordance with the principles of good clinical practice ${ }^{26}$ and the Declaration of Helsinki (Tokyo amendments). The study was conducted in two phases: a healing phase and a maintenance phase, each of which included three double-blind parallel treatment groups.

\section{Healing Phase}

Patients of either sex who were 18 to 85 years of age and who had any condition requiring continuous treatment with oral or rectal NSAIDs above a predetermined minimal dose (there was no maximal dose) underwent endoscopy after providing informed consent. The minimal (and mean) daily oral doses of the commonly used NSAIDs were $50 \mathrm{mg}(129 \mathrm{mg}$ ) for diclofenac, 100 $\mathrm{mg}(137 \mathrm{mg})$ for ketoprofen, and $500 \mathrm{mg}(844 \mathrm{mg})$ for naproxen. Patients who were found to have any or all of the following were invited to enter the study by giving further written informed consent: ulcer, defined as a mucosal break at least $3 \mathrm{~mm}$ in diameter with definite depth in the stomach, duodenum, or both; more than 10 gastric erosions; and more than 10 duodenal erosions. The main exclusion criteria were concurrent reflux esophagitis at stage 3 or 4 according to the Savary-Miller classification, clinically important upper gastrointestinal bleeding, pyloric stenosis, a history of gastric surgery, or gastrointestinal disorders that might impair the absorption of the study drugs. Patients could enter the study if they were taking glucocorticoids at a dose $\leqslant 10$ $\mathrm{mg}$ of prednisolone (or its equivalent).

Patients continued to take NSAIDs and were randomly assigned (in blocks of three at each site) to receive $20 \mathrm{mg}$ or $40 \mathrm{mg}$ of omeprazole (Losec, Astra Hässle, Mölndal, Sweden) once daily in the morning or $200 \mu \mathrm{g}$ of misoprostol (Cytotec, Searle, Skokie, Ill.) four times daily. All drugs were given orally. The patients underwent endoscopy after four weeks of treatment and again at eight weeks if the lesions were not healed. The primary end point in this phase was treatment success (defined before the study began as the absence of ulcers in the stomach or duodenum and the presence of fewer than five gastric erosions, fewer than five duodenal erosions, and not more than mild symptoms of dyspepsia). Erosions were assessed with a modified Lanza scale used in previous studies ${ }^{27,28}$; clinically significant healing of erosions corresponded to a 2-point reduction in the Lanza grade (from a grade of 4 , defined as the presence of more than 10 erosions, to a grade of 2 , defined as the presence of fewer than 5 erosions). Patients without this level of healing at eight weeks received open treatment with $40 \mathrm{mg}$ of omeprazole daily for a further four to eight weeks. We also assessed the healing rates of all ulcers, larger ulcers $(\geqslant 5 \mathrm{~mm})$, gastric ulcers, duodenal ulcers, and erosions, and changes in dyspeptic symptoms and the quality of life.

\section{Maintenance Phase}

Patients in whom treatment was successful during the healing phase were randomly assigned on a 2:2:1 basis (in blocks of five at each site) to receive $20 \mathrm{mg}$ of omeprazole once daily, $200 \mu \mathrm{g}$ of misoprostol twice daily, or placebo. Randomization was not formally balanced according to treatment assignment in the healing phase. Patients were followed for six months or until the primary end point, treatment failure (defined before the study began as the development of any of the following: an ulcer, more than 10 gastric erosions, more than 10 duodenal erosions, at least moderate symptoms of dyspepsia, or adverse events resulting in the discontinuation of treatment). We also assessed the rates of relapse of all ulcers, larger ulcers, gastric ulcers, duodenal ulcers, and erosions and the quality of life. When a patient withdrew from the study, both randomized treatment and assessment of its effectiveness ceased.

\section{Assessments}

The patients were assessed clinically and endoscopically monthly during the healing phase and at one, three, and six months during the maintenance phase or as clinically required. Antral Helicobacter pylori status was determined at base line with the urease enzyme test (CLO test, Delta West, Bentley, Australia). Patients infected with $H$. pylori were not treated for this infection, because there was no evidence that treatment was beneficial 29,30 and because $H$. pylori-stimulated mucosal synthesis of prostaglandin may be beneficial for NSAID-associated ulcers. ${ }^{31}$ Biopsies of gastric ulcers were performed to rule out the possibility of malignant conditions. We assessed compliance by counting the number of tablets or capsules the patients returned.

At each assessment the patients were asked whether they had had specific dyspeptic symptoms (epigastric or abdominal pain, heartburn, nausea, vomiting, upper abdominal bloating, and an empty feeling in the stomach) during the preceding seven days and to describe any upper gastrointestinal symptoms they had on the day of the visit. These symptoms were graded at each visit as absent, mild (easily tolerated), moderate (interfering with normal activities), or severe (incapacitating; leaving the patient unable to perform normal activities). During the first four weeks of the study, the patients also completed symptom diary cards recording the presence or absence of epigastric or abdominal pain and heartburn during the day and at night.

Safety assessments were based on the reported symptoms, adverse events, and the results of standard blood screening. Quality of life was assessed at 73 centers in nine countries. Each patient completed three questionnaires - the Nottingham Health Profile, the Psychological General Well-Being Index, and the Gastrointestinal Symptom Rating Scale - at entry and monthly during the healing phase and after one and six months of maintenance treatment (or when treatment was discontinued). The Nottingham Health Profile evaluates the perceived effect of chronic disease in terms of a patient's emotions, ability to sleep, social isolation, energy level, level of pain, and level of mobility. ${ }^{32}$ The scores can range from 0 (no problem or distress) to 100 (worst possible problem or distress). The Nottingham Health Profile also evaluates, in a "yes" or "no" format, the effect of health-related problems on the patient's work, home life, social life, sex life, and leisure activities. The Psychological General Well-Being Index measures subjective well-being or distress in terms of anxiety, depressed mood, positive well-being, self-control, and general health and vitality on a 6-point Likert scale. ${ }^{33}$ The worst possible score is 22 , and the best possible is 132. The Gastrointestinal Symptom Rating Scale assesses indigestion, reflux, constipation, abdominal pain, and diarrhea on a 7-point Likert scale. ${ }^{34} \mathrm{~A}$ mean item value is calculated in which a score of 1 indicates no bothersome symptoms and a score of 7 extremely bothersome symptoms.

\section{Statistical Analysis}

We compared the overall rates of treatment success and healing of specific lesions during the healing phase using a MantelHaenszel life-table test with data obtained at four and eight weeks. We performed multiple logistic-regression analysis of prognostic factors that may have influenced the success of treatment at four weeks: treatment, base-line lesion, ulcer size, H. pylori status at base line, blood group, type of arthritic disease, smoking status, age, and sex. Symptom scores recorded at four weeks, stratified according to severity at base line, were compared with use of Wilcoxon's test, and diary-card scores with use of Student's t-test. The length of time until treatment failure during the maintenance phase was compared by the log-rank test. Possible prognostic factors were assessed by the Cox proportional-hazards regression method. In each phase of the study, changes in the scores of the 
quality-of-life assessments from base line to the most recent visit were compared between treatment groups with an unpaired t-test.

The study was designed to investigate the two doses of omeprazole and misoprostol as separate treatments and to have 80 percent power to detect differences between any of the three treatments at a level of 0.017 (with Bonferroni's correction) on the basis of estimated relapse rates during the maintenance phase of 60 percent in the placebo group, 35 percent in the misoprostol group, and 20 percent in the omeprazole group. The primary efficacy analysis used an intention-to-treat approach that included all patients meeting major entry criteria who took at least one dose of medication. The safety analysis included all patients who received at least one dose of medication and for whom there were safety data, regardless of whether they met the entry criteria for the trial. For these reasons there were small differences in the numbers of patients included in the efficacy and safety analyses. No interim analyses were conducted. For cases in which data censoring, arising from the use of life-table analysis, prevented valid statistical comparisons of subgroups, $\mathrm{P}$ values are not presented.

\section{RESULTS}

\section{Characteristics of the Patients}

A total of 935 patients were enrolled in the healing phase, of whom 921 had efficacy data that could be evaluated. Of 732 patients enrolled in the maintenance phase, 725 had efficacy data that could be evaluated. In the healing phase, seven patients who did not use NSAIDs, three who had no ulcers and $\leqslant 10$ erosions, and four with major deviations from the inclusion criteria could not be evaluated. In the maintenance phase, two patients who received no trial drug, one whose treatment was unknown, one with major deviations from the inclusion criteria, and three who declined to continue the study could not be evaluated.

The treatment groups were well balanced with regard to demographic characteristics, underlying diseases, and $H$. pylori status (Table 1 ) and, in the maintenance phase, with regard to treatment received during the healing phase (data not shown). The most commonly used NSAIDs at entry were diclofenac (23 percent of the patients), naproxen $(22$ percent), and ketoprofen (16 percent). Approximately two thirds of the patients were enrolled in the study because of ulcers, two thirds of which were

Table 1. Base-Line Characteristics of the Patients Included in the Efficacy Analysis.

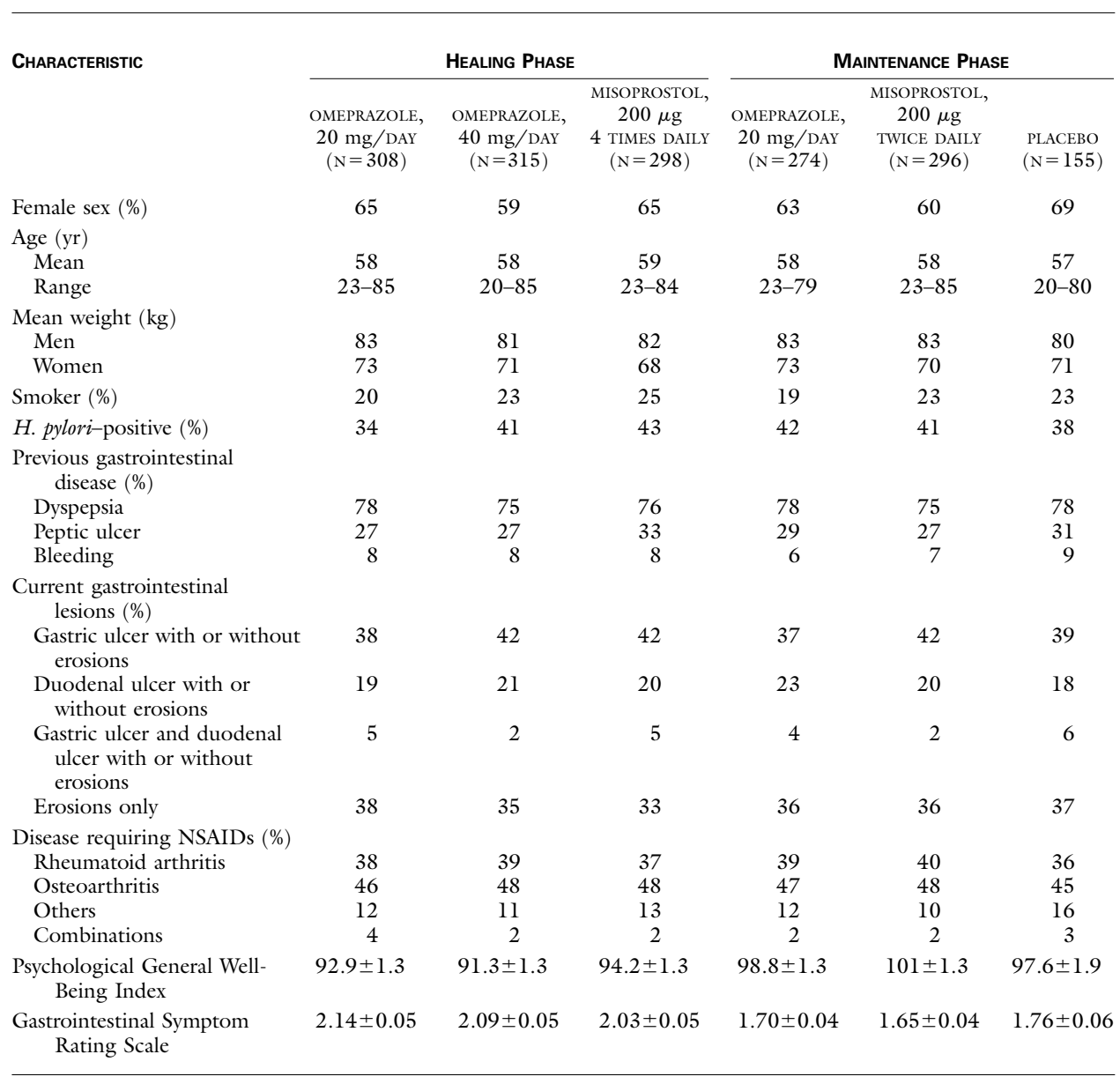

*Plus-minus values are means \pm SE. 
gastric; 83 percent of all ulcers were $5 \mathrm{~mm}$ or more in diameter. Most patients had rheumatoid arthritis or osteoarthritis.

\section{Healing Phase}

\section{Treatment Success}

During the eight weeks of the healing phase, the rates of treatment success were similar among the group given $20 \mathrm{mg}$ of omeprazole (76 percent [ 233 of 308 patients], $\mathrm{P}=0.76$ for the comparison with 40 $\mathrm{mg}$ of omeprazole), the group given $40 \mathrm{mg}$ of omeprazole ( 75 percent [ 237 of 315$]$ ), and the group given misoprostol (71 percent [ 212 of 298 ], $\mathrm{P}=0.37$ for the comparison with $20 \mathrm{mg}$ of omeprazole and $\mathrm{P}=0.24$ for the comparison with $40 \mathrm{mg}$ of omeprazole). When the rates of treatment success were analyzed to include as treatment failures all patients whose data could not be evaluated the respective rates were 75 percent, 75 percent, and 71 percent.

At eight weeks, healing of gastric ulcers was significantly more common among patients treated with $20 \mathrm{mg}$ of omeprazole (87 percent [102 of 117 patients]) than among those given misoprostol (73 percent [91 of 125], $\mathrm{P}=0.004$ ) (Fig. 1). The healing rate for $40 \mathrm{mg}$ of omeprazole was 80 percent (105 of 132 patients, $\mathrm{P}=0.14$ for the comparison with misoprostol). The healing rates for $20 \mathrm{mg}$ of omeprazole, $40 \mathrm{mg}$ of omeprazole, and misoprostol were 85 percent (111 of 131 patients), 79 percent (111 of 140), and 74 percent (104 of 141), respectively, when patients with concurrent gastric and duodenal ulcers were included and 88 percent $(78$ of 89 patients), 78 percent ( 83 of 107$)$, and 72 percent (71 of 99), respectively, when patients with gastric ulcers of $5 \mathrm{~mm}$ or more in diameter were analyzed. The rates of healing of duodenal ulcers were also significantly higher in the groups given 20 mg of omeprazole (93 percent [55 of 59 patients]) or $40 \mathrm{mg}$ of omeprazole ( 89 percent [58 of 65]) than in the group given misoprostol (77 percent [ 46 of 60], $\mathrm{P}<0.001$ for each comparison) (Fig. 1). A similar pattern of results was seen when patients with concurrent gastric ulcers initially were included in the analysis - 93 percent ( 68 of 73 patients), 89 percent (65 of 73), and 79 percent (60 of 76), respectively - as well as in the analysis of duodenal ulcers that were $5 \mathrm{~mm}$ or more in diameter: 94 percent ( 47 of 50 patients), 89 percent ( 48 of 54 ), and 77 percent ( 44 of 57 ), respectively. By contrast, erosions healed significantly better during the eight weeks with misoprostol (87 percent [84 of $97 \mathrm{pa}$ tients]) than with $20 \mathrm{mg}$ of omeprazole (77 percent [91 of 118], $\mathrm{P}<0.001$ ) or $40 \mathrm{mg}$ of omeprazole (79 percent [86 of 109], $\mathrm{P}=0.01$ ) (Fig. 1).

Treatment was judged unsuccessful in few patients at eight weeks because of the persistence of at least moderate symptoms of dyspepsia alone: five patients in the group given $20 \mathrm{mg}$ of omeprazole (1.6 percent), two in the group given $40 \mathrm{mg}$ of omeprazole (0.6 percent), and three in the group given misoprostol (1.0 percent). Therefore, the major reason for treatment failure was lack of healing of ulcers or erosions.

\section{Prognostic Factors}

The favorable prognostic factors were the presence of duodenal ulcers $(\mathrm{P}=0.04)$ or erosions alone $(\mathrm{P}=0.05)$ at base line rather than gastric ulcers, and a positive test (vs. a negative test) for $H$. pylori $(\mathrm{P}=0.05)$. At eight weeks, the respective rates of
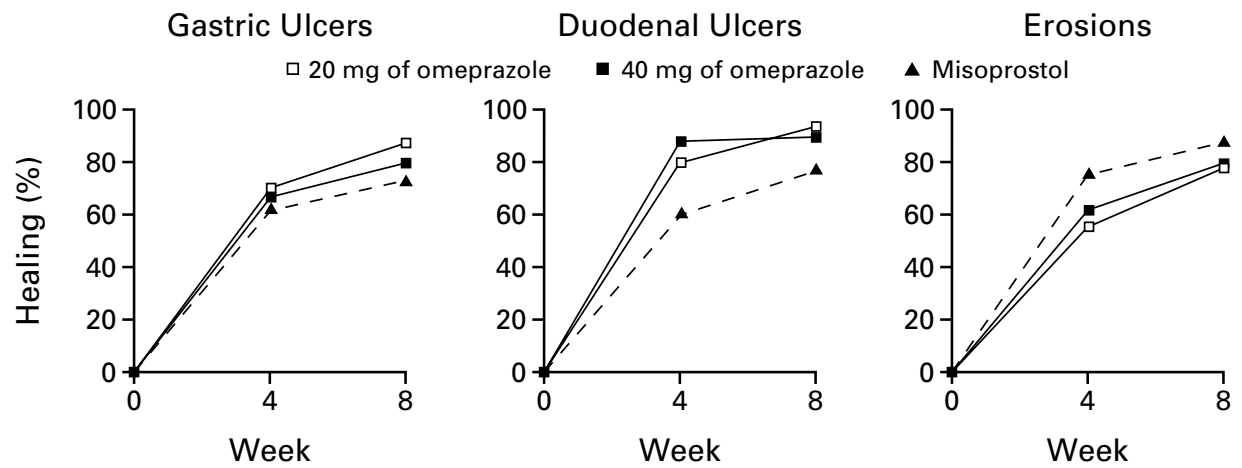

No. of Patients Healed/Total No.

$\begin{array}{ccccccc}\begin{array}{c}20 \text { mg of } \\ \text { omeprazole }\end{array} & 82 / 117 & 102 / 117 & 47 / 59 & 55 / 59 & 65 / 118 & 91 / 118 \\ \begin{array}{c}40 \text { mg of } \\ \text { omeprazole }\end{array} & 88 / 132 & 105 / 132 & 57 / 65 & 58 / 65 & 67 / 109 & 86 / 109 \\ \begin{array}{c}\text { Misoprostol } \\ \text { s }\end{array} & 77 / 125 & 91 / 125 & 36 / 60 & 46 / 60 & 73 / 97 & 84 / 97\end{array}$

Figure 1. Cumulative Rates of Healing of Gastric Ulcers, Duodenal Ulcers, and Erosions at Four and Eight Weeks during Treatment with $20 \mathrm{mg}$ of Omeprazole Daily, $40 \mathrm{mg}$ of Omeprazole Daily, or $200 \mu \mathrm{g}$ of Misoprostol Four Times Daily. 
treatment success among $H$. pylori-negative patients and $H$. pylori-positive patients were 74 percent (112 of 151 patients) and 69 percent ( 80 of 116$)$ in the group given misoprostol, 73 percent (132 of 181) and 83 percent ( 79 of 95 ) in the group given $20 \mathrm{mg}$ of omeprazole, and 70 percent (117 of 167) and 83 percent (95 of 114) in the group given $40 \mathrm{mg}$ of omeprazole.

\section{Dyspeptic Symptoms}

The proportion of patients with moderate-tosevere symptoms of dyspepsia after four weeks of treatment declined from 38 percent (at base line) to 11 percent in the misoprostol group, from 45 percent to 11 percent in the group given $20 \mathrm{mg}$ of omeprazole $(\mathrm{P}=0.08$ for the comparison with misoprostol), and from 45 percent to 6 percent in the group given $40 \mathrm{mg}$ of omeprazole $(\mathrm{P}=0.004$ for the comparison with misoprostol and $\mathrm{P}=0.25$ for the comparison with $20 \mathrm{mg}$ of omeprazole). Diarycard data also showed that patients had significantly less abdominal pain with omeprazole than with misoprostol. Abdominal pain was reported on a mean ( \pm SE) of $43 \pm 2$ percent of days with $20 \mathrm{mg}$ or 40 mg of omeprazole, as compared with a mean of $50 \pm 2$ percent of days with misoprostol $(\mathrm{P}=0.02$ for both comparisons). Heartburn was recorded on $16 \pm 1$ percent of days with $20 \mathrm{mg}$ of omeprazole and $14 \pm \mathrm{l}$ percent of days with $40 \mathrm{mg}$ of omeprazole, as compared with $29 \pm 2$ percent of days with misoprostol ( $\mathrm{P}<0.001$ for both comparisons).

\section{Quality-of-Life Evaluation}

Quality-of-life evaluations were completed by 212 patients in the group given $20 \mathrm{mg}$ of omeprazole, 209 patients in the group given $40 \mathrm{mg}$ of omeprazole, and 185 patients in the misoprostol group. Patients treated with $20 \mathrm{mg}$ of omeprazole had significantly greater improvements in scores on the Gastrointestinal Symptom Rating Scale than patients treated with misoprostol: total score, -0.47 as compared with $-0.20(\mathrm{P}<0.001)$; reflux score, -0.82 as compared with $-0.33(\mathrm{P}<0.001)$; abdominal-pain score, -0.69 as compared with $-0.35(\mathrm{P}<0.001)$; and indigestion score, -0.48 as compared with $-0.30(\mathrm{P}=0.04)$. The $40-\mathrm{mg}$ dose of omeprazole was associated with significant improvement in the total score $(-0.36, \mathrm{P}=0.008$ for the comparison with misoprostol) and the reflux score $(-0.75, \mathrm{P}<$ 0.001 for the comparison with misoprostol). Patients treated with misoprostol had worsening diarrhea scores $(+0.22)$, in contrast to those treated with $20 \mathrm{mg}$ of omeprazole $(-0.24, \mathrm{P}<0.001)$ or 40 $\mathrm{mg}$ of omeprazole $(-0.06, \mathrm{P}<0.001)$. The sleep score on the Nottingham Health Profile improved more with misoprostol than with $20 \mathrm{mg}$ of omeprazole $(-8.6$ as compared with $-3.1 ; \mathrm{P}=0.03)$. There were no other significant differences between groups.

\section{Maintenance Phase}

\section{Relapse}

Kaplan-Meier estimates of the rates of remission during the maintenance phase are shown in Figure 2 . The estimated proportion of patients in remission at six months was 61 percent among those taking 20 mg of omeprazole, as compared with 48 percent among those taking $200 \mu \mathrm{g}$ of misoprostol twice daily $(\mathrm{P}=0.001)$ and 27 percent among those taking placebo $(\mathrm{P}<0.001$ for the comparisons with omeprazole and misoprostol).

Thirty-two percent of patients taking placebo $(50$ of 155) had gastric ulcers at relapse, as compared with 10 percent of patients taking misoprostol (31 of 296) and 13 percent of those taking omeprazole (35 of 274). The respective rates of ulcers of $5 \mathrm{~mm}$ or more in diameter at relapse were 20 percent (31 of 155 patients), 8 percent (23 of 296), and 8 percent (21 of 274). Duodenal ulcers developed in 12 percent of patients given placebo (19 of 155), as compared with 10 percent of those given misoprostol (30 of 296) and 3 percent of those given omeprazole (7 of 274). The respective rates for ulcers that were $5 \mathrm{~mm}$ or more in diameter were 10 percent $(15$ of 155 patients), 9 percent ( 26 of 296 ), and 3 percent ( 7 of 274). Fourteen percent of patients taking placebo (2l of 155), 7 percent of those taking misoprostol (21 of 296), and 12 percent of those taking omeprazole (34 of 274) had multiple erosions at relapse. The site and nature of the lesion at relapse tended to be the same as those at base line. Of the

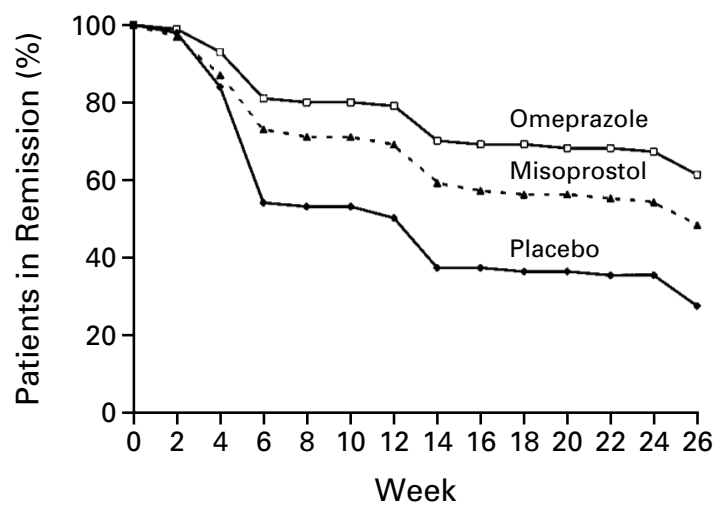

No. AT RISK OF RELAPSE

$\begin{array}{lllll}\text { Omeprazole } & 274 & 253 & 203 & 149\end{array}$

$\begin{array}{lllll}\text { Misoprostol } & 296 & 252 & 193 & 129\end{array}$

$\begin{array}{lllll}\text { Placebo } & 155 & 130 & 69 & 41\end{array}$

Figure 2. Kaplan-Meier Estimates of the Rates of Remission among Patients Treated with $20 \mathrm{mg}$ of Omeprazole Daily, 200 $\mu \mathrm{g}$ of Misoprostol Twice Daily, or Placebo for up to 26 Weeks. $\mathrm{P}<0.001$ for the comparison of omeprazole with placebo by the log-rank test, and $\mathrm{P}=0.001$ for the comparison of omeprazole with misoprostol by the log-rank test. 
patients with gastric ulcers at relapse, 73 percent had gastric ulcers at presentation. The respective values for duodenal ulcers and erosions were 72 percent and 61 percent.

\section{Prognostic Factors Influencing Remission}

Factors associated with a higher probability of continued remission were treatment with omeprazole rather than misoprostol $(\mathrm{P}=0.005)$ or placebo $(\mathrm{P}<0.001)$, the presence of erosions alone at base line $(\mathrm{P}=0.05)$, nonsmoking status $(\mathrm{P}=0.001)$, and a positive test for $H$. pylori $(\mathrm{P}=0.03)$. The estimated proportions of $H$. pylori-positive patients and $H$. pylori-negative patients in remission at six months were 74 percent and 54 percent, respectively, in the omeprazole group, 44 percent and 52 percent in the misoprostol group, and 27 percent and 28 percent in the placebo group.

\section{Quality-of-Life Evaluation}

Quality-of-life evaluations were completed by 188 patients in the omeprazole group, 193 patients in the misoprostol group, and 95 patients in the placebo group. The mean values for the following scores on the Gastrointestinal Symptom Rating Scale improved in the omeprazole group and worsened in the misoprostol group: total score, -0.06 as compared with $+0.15(\mathrm{P}<0.001)$; reflux score, -0.04 as compared with $+0.35(\mathrm{P}<0.001)$; abdominal-pain score, -0.15 as compared with $+0.08(\mathrm{P}=$ $0.003)$; and indigestion score, -0.10 as compared with $+0.12(\mathrm{P}=0.008)$. Placebo was associated with worse scores than omeprazole for control of abdominal pain (score, +0.12 as compared with $-0.15 ; \mathrm{P}=$ $0.007)$ and reflux $(+0.36$ as compared with -0.04 ; $\mathrm{P}=0.002)$ and better scores than misoprostol for controlling diarrhea $(-0.09$ as compared with +0.12 ; $\mathrm{P}=0.04)$.

\section{Safety and Adverse Events}

During the healing phase, more patients in the misoprostol group (59 percent [175 of 299]) reported adverse events than in the group given $20 \mathrm{mg}$ of omeprazole (48 percent [148 of 311]) or the group given $40 \mathrm{mg}$ of omeprazole (46 percent [ 147 of 319]). More patients in both phases stopped taking misoprostol because of adverse events or a lack of efficacy (Table 2). A perforated duodenal ulcer developed in one patient during the maintenance phase after 31 days of placebo. She underwent surgery and recovered.

\section{DISCUSSION}

Our study was designed to compare omeprazole and misoprostol at standard recommended doses as healing and prophylactic treatments for patients taking NSAIDs. The rates of treatment success with 20 $\mathrm{mg}$ or $40 \mathrm{mg}$ of omeprazole daily were similar to
Table 2. Incidence of Moderate-to-Severe Adverse Events in All Patients and Reasons for Discontinuation of Treatment And Follow-Up in Patients InCluded IN THE EFFICACY ANALYSIS.

\begin{tabular}{|c|c|c|c|}
\hline \multirow[t]{2}{*}{ VARIABLE } & \multicolumn{3}{|c|}{ Healing Phase } \\
\hline & $\begin{array}{l}\text { OMEPRAZOLE, } \\
20 \mathrm{mg} / \mathrm{DAY} \\
(\mathrm{N}=31 \mathrm{l})\end{array}$ & $\begin{array}{l}\text { OMEPRAZOLE, } \\
40 \mathrm{mg} / \mathrm{DAY} \\
(\mathrm{N}=319)\end{array}$ & $\begin{array}{l}\text { MISOPROSTOL, } \\
200 \mu \mathrm{g} \\
4 \text { TIMES DAILY } \\
(\mathrm{N}=299)\end{array}$ \\
\hline $\begin{array}{l}\text { Mean duration of expo- } \\
\text { sure to drug (days) }\end{array}$ & 39 & 38 & 35 \\
\hline \multicolumn{4}{|l|}{$\begin{array}{l}\text { Most common adverse } \\
\text { events ( } \% \text { of patients) }\end{array}$} \\
\hline Diarrhea & 4.5 & 5.3 & 11.4 \\
\hline Abdominal pain & 1.9 & 3.1 & 8.0 \\
\hline Flatulence & 1.6 & 1.3 & 3.7 \\
\hline $\begin{array}{l}\text { Respiratory tract infec- } \\
\text { tion }\end{array}$ & 1.3 & 1.6 & 2.7 \\
\hline Headache & 2.9 & 1.9 & 1.0 \\
\hline Arthritis & 2.3 & 1.6 & 1.3 \\
\hline $\begin{array}{l}\text { Discontinuation of treat- } \\
\text { ment (\% of patients) }\end{array}$ & 9.9 & 10.6 & 16.9 \\
\hline $\begin{array}{l}\text { Adverse event or lack of } \\
\text { efficacy }\end{array}$ & 4.8 & 5.6 & 9.9 \\
\hline \multirow[t]{3}{*}{ Other reasons* } & 5.1 & 5.0 & 7.0 \\
\hline & \multicolumn{3}{|c|}{ Maintenance Phase } \\
\hline & $\begin{array}{l}\text { OMEPRAZOLE, } \\
20 \mathrm{mg} / \mathrm{DAY} \\
(\mathrm{N}=275)\end{array}$ & $\begin{array}{c}\text { MISOPROSTOL } \\
200 \mu \mathrm{g} \text { TWICE } \\
\text { DAILY } \\
(\mathrm{N}=297)\end{array}$ & $\begin{array}{l}\text { PLACEBO } \\
(\mathrm{N}=155)\end{array}$ \\
\hline $\begin{array}{l}\text { Mean duration of expo- } \\
\text { sure to drug (days) }\end{array}$ & 134 & 116 & 85 \\
\hline $\begin{array}{l}\text { Most common adverse } \\
\text { events (\% of patients) }\end{array}$ & & & \\
\hline Diarrhea & 7.6 & 8.4 & 4.5 \\
\hline Abdominal pain & 5.1 & 4.7 & 5.8 \\
\hline Arthritis & 4.4 & 3.4 & 3.2 \\
\hline Flatulence & 2.5 & 3.4 & 3.2 \\
\hline Pain & 2.2 & 2.7 & 4.5 \\
\hline $\begin{array}{l}\text { Respiratory tract infec- } \\
\text { tion }\end{array}$ & 2.5 & 3.4 & 0.6 \\
\hline $\begin{array}{l}\text { Discontinuation of treat- } \\
\text { ment (\% of patients) }\end{array}$ & 12.1 & 16.8 & 10.3 \\
\hline Adverse event & 3.9 & 7.7 & 1.9 \\
\hline Other reasons $\dagger$ & 8.2 & 9.1 & 8.4 \\
\hline
\end{tabular}

*The main other reason was unwillingness to continue in the study (four patients in the group given $20 \mathrm{mg}$ of omeprazole, eight in the group given $40 \mathrm{mg}$ of omeprazole, and seven in the misoprostol group).

†The main other reason was unwillingness to continue in the study (11 patients in the omeprazole group, 10 in the misoprostol group, and 8 in the placebo group).

that with $200 \mu \mathrm{g}$ of misoprostol four times daily during the healing phase, but $20 \mathrm{mg}$ of omeprazole daily was more effective than $200 \mu \mathrm{g}$ of misoprostol twice daily in the maintenance phase and was better tolerated in both phases. The 20-mg dose of omeprazole was associated with better quality-of-life scores on the Gastrointestinal Symptom Rating Scale and fewer withdrawals from treatment. The 40-mg dose of omeprazole ( 75 percent rate of treatment success) offered no additional healing benefit over that af- 
forded by the $20-\mathrm{mg}$ dose, but it resulted in slightly better scores on some assessments of symptoms. In an attempt to replicate clinically important dilemmas, we studied patients with clinically significant lesions at initial endoscopy, who are at higher risk for ulcers than those without lesions. ${ }^{25}$ Omeprazole is also highly effective in preventing NSAID-associated ulcers when used empirically ${ }^{35}$ or in patients who are initially free of ulcers. ${ }^{36}$

Ulcers, multiple erosions, or both were criteria for enrollment and treatment failure, because erosions can progress to ulcers ${ }^{37}$ and can themselves lead to gastrointestinal bleeding. Approximately two thirds of the patients had ulcers (mostly gastric), 83 percent of which were at least $5 \mathrm{~mm}$ in diameter. Omeprazole healed gastric and duodenal ulcers more effectively than misoprostol, whereas misoprostol was more effective in patients with erosions alone. These relations were seen for both $\mathrm{H}$. pyloripositive and $H$. pylori-negative patients. In the maintenance phase, similar numbers of duodenal ulcers developed in patients taking misoprostol and those taking placebo, but very few developed in those taking omeprazole. Omeprazole and misoprostol were similarly efficacious in preventing gastric ulcers, whereas misoprostol was better able to prevent erosions. It is possible that higher doses of misoprostol would have been more effective but less well tolerated.

There was a strong tendency for the lesions noted at relapse to be in the same location and of the same type as those seen initially. Local mucosal influences rather than more general risk factors may therefore account for the higher rates of NSAID-associated ulceration among patients with a history of ulcers.6,38

There are four plausible explanations for the significantly better prognosis associated with a positive test for $H$. pylori and the increased effectiveness of omeprazole in infected patients. First, H. pylori stimulates the synthesis of mucosal prostaglandins in NSAID users, ${ }^{31}$ which could enhance healing and reduce relapse (but not in those treated with exogenous prostaglandins). Second, intragastric $\mathrm{pH}$ is higher during omeprazole therapy in $\mathrm{H}$. pylori-positive than in $H$. pylori-negative patients. ${ }^{39,40}$ Third, NSAID-associated ulcers might be of two kinds: true primary ulcers caused by NSAID use and $H$. $p y$ lori-associated ulcers exacerbated by NSAID use. ${ }^{41}$ Finally, we studied a selected subgroup of patients, and we do not know whether our results can be generalized to an unselected group of patients.

Misoprostol has been shown to prevent NSAIDassociated gastrointestinal complications. ${ }^{15}$ Omeprazole has not, but our findings suggest that it would. To challenge this view, one would have to argue that omeprazole selectively failed to prevent lesions most likely to cause complications. However, in no subgroup examined was omeprazole less effective as ul- cer prophylaxis than misoprostol. Previous studies have shown a reduction in ulcer bleeding with acid suppression. $.2,43$

The availability of omeprazole as a better-tolerated alternative to misoprostol may increase the use of prophylactic therapy. Since the presence of symptoms is not a reliable means of determining whether NSAID users have ulcers, ${ }^{44}$ risk factors such as age, history, type and dose of NSAIDs, and concurrent therapy with warfarin or glucocorticoids should be assessed in individual patients, 6,738 and should be used to develop rational recommendations for prophylaxis in patients who require long-term treatment with NSAIDs.

Supported by Astra Hässle, Mölndal, Sweden.

Dr. Yeomans serves as a consultant for Searle Australia.

This article is dedicated to the memory of Mr. Eugen Taure, who died on July 9, 1996

We are indebted to Dr. M. Frame for valuable help with the drafting and editing of the manuscript, to all study personnel who took part at each clinic, and to all those who were involved in packing the study drugs, monitoring the study, and processing the data.

\section{APPENDIX}

The following persons also participated in the OMNIUM Study: Steering Committee - C. Hawkey, A. Swannell, N. Yeomans, S. Eriksson, A. Walan; Coordinating Group - I. Florén, M. Lamm, J. Lindfeldt, G. Långström, J. Naesdal, E. Taure (deceased), I. Wiklund, I. Wilson; Australia - R. Smallwood, B. Mitchell, F. Narielvala, M. Ward, R. Bradbear, G. Daskalopoulos; Belgium - M. Deltenre, J. Belaiche, J. Janssens, L. Harlet, G. Vantrappen; Canada - R. Fedorak, B. Salena, G. Aumais, C. Dallaire, L. Cohen, D. Weiner-Baron, R. Bridges, B. Hoffert, M. Willans, J. Thorne, G. Morin, B. El Safadi, L. DaCosta, P. Smith, W. Olszynski, E. Smith; Ireland - C. O'Morain; France - P. Carayon, G. Thiefin, J. Escourrou, J.-P. Bader; Germany - W. Bolten, K. Helmke, I. Auer, K.-J. Goerg, R. Dreher, E. Gromnica-Ihle, E. Zinsser; the Netherlands - G. Bruyn, W. Dekker, F. Vismans; New Zealand - R. Ali; Poland - K. Bernacka, A. Filipowicz-Sosnowska, I. Zimmermann-Górska, I. FiedorowiczFabrycy; Slovak Republic - M. Pijāk; Spain - A. Lanas, L. Rodrigo, M. Barenys, R. Uribarrena; Sweden - A. Aly, S. Back, L.-K. Enander, M. Hellblom, K. Sjölund, L. Thulin, K. Ung, H. Nyhlin, B. Philipson, H. Tanghöj, L. Knutsson, O. Anker-Hansen, J. Persson, R. Jansson; United Kingdom - K. Bardhan, D. Rampton, J. Hosie, N. Krasner, R. Chapman, K. Miloszewcki; United States - D. Ballard, B. Sahba, J. Cuervo, M. Eisner, J. Fitterer, S. Gaddam, C. Howden, D. Kogut, F. Lanza, F. Lushine, M. Mellow, R. Pruitt, S. Faruqui, H. Siegel, B. Winston, R. Krause, M. Zuckerman, A. Gottesman.

\section{REFERENCES}

1. Paakkari H. Epidemiological and financial aspects of the use of non-steroidal anti-inflammatory analgesics. Pharmacol Toxicol 1994;75:Suppl 2: 56-9.

2. Huang J, Hunt RH. A clinician's view of strategies for preventing NSAID-induced gastrointestinal ulcers. Inflammopharmacology 1996;4: 17-30.

3. Wolfe F, Kleinheksel SM, Spitz PW, et al. A multicenter study of hospitalization in rheumatoid arthritis: frequency, medical-surgical admissions, and charges. Arthritis Rheum 1986;29:614-9.

4. Hazleman BL. Incidence of gastropathy in destructive arthropathies. Scand J Rheumatol Suppl 1989;78:1-4.

5. Hawkey CJ. Non-steroidal anti-inflammatory drugs and peptic ulcers. BMJ 1990;300:278-84. [Erratum, BMJ 1990;300:764.]

6. Gabriel SE, Jaakkimainen L, Bombardier C. Risk for serious gastrointestinal complications related to use of nonsteroidal anti-inflammatory drugs: a meta-analysis. Ann Intern Med 1991;115:787-96.

7. Henry D, Lim LL-Y, Garcia Rodriguez LA, et al. Variability in risk of gastrointestinal complications with individual non-steroidal anti-inflammatory drugs: results of a collaborative meta-analysis. BMJ 1996;312:1563-6. 
8. Griffin MR, Piper JM, Daugherty JR, Snowden M, Ray WA. Nonsteroidal anti-inflammatory drug use and increased risk for peptic ulcer disease in elderly persons. Ann Intern Med 1991;114:257-63.

9. Langman MJS, Weil J, Wainwright P, et al. Risks of bleeding peptic ulcer associated with individual non-steroidal anti-inflammatory drugs. Lancet 1994;343:1075-8.

10. Fries JF. NSAID gastropathy: the second most deadly rheumatic disease? Epidemiology and risk appraisal. J Rheumatol Suppl 1991;28:6-10. 11. McCarthy DM. Nonsteroidal antiinflammatory drug-induced ulcers: management by traditional therapies. Gastroenterology 1989;96:Suppl: 662-74

12. Elliott SL, Yeomans ND, Buchanan RRC, Smallwood RA. Efficacy of 12 months' misoprostol as prophylaxis against NSAID-induced gastric ulcers: a placebo-controlled trial. Scand J Rheumatol 1994;23:171-6.

13. Graham DY, Agrawal NM, Roth SH. Prevention of NSAID-induced gastric ulcer with misoprostol: multicentre, double-blind, placebo-controlled trial. Lancet 1988;2:1277-80.

14. Walt RP. Misoprostol for the treatment of peptic ulcer and antiinflammatory-drug-induced gastroduodenal ulceration. N Engl J Med 1992;327: 1575-80.

15. Silverstein FE, Graham DY, Senior JR, et al. Misoprostol reduces serious gastrointestinal complications in patients with rheumatoid arthritis receiving nonsteroidal anti-inflammatory drugs: a randomized, double-blind, placebo-controlled trial. Ann Intern Med 1995;123:241-9.

16. Scheiman JM. Pathogenesis of gastroduodenal injury due to nonsteroidal antiinflammatory drugs: implications for prevention and therapy.

Semin Arthritis Rheum 1992;21:201-10.

17. Brooks PM, Day RO. Nonsteroidal antiinflammatory drugs - differ ences and similarities. N Engl J Med 1991;324:1716-25. [Erratum, N Engl J Med 1991;325:747.]

18. Davenport HW. Gastric mucosal injury by fatty and acetylsalicylic acids. Gastroenterology 1964;46:245-53.

19. Chvasta TE, Cooke AR. The effect of several ulcerogenic drugs on the canine gastric mucosal barrier. J Lab Clin Med 1972;79:302-15.

20. McCormack K, Brune $\mathrm{K}$. Classical absorption theory and the development of gastric mucosal damage associated with the non-steroidal antiinflammatory drugs. Arch Toxicol 1987;60:261-9.

21. Schoen RT, Vender RJ. Mechanisms of nonsteroidal anti-inflammatory drug-induced gastric damage. Am J Med 1989;86:449-58.

22. Daneshmend TK, Stein AG, Bhaskar NK, Hawkey CJ. Abolition by omeprazole of aspirin induced gastric mucosal injury in man. Gut 1990; 31:514-7.

23. Scheiman JM, Behler EM, Loeffler KM, Elta GH. Omeprazole ameliorates aspirin-induced gastroduodenal injury. Dig Dis Sci 1994;39:97103.

24. Walan A, Bader J-P, Classen $M$, et al. Effect of omeprazole and ranitidine on ulcer healing and relapse rates in patients with benign gastric ulcer. N Engl J Med 1989;320:69-75

25. Hudson N, Taha AS, Russell RI, et al. Famotidine for healing and maintenance in nonsteroidal anti-inflammatory drug-associated gastroduodenal ulceration. Gastroenterology 1997;112:1817-22.

26. EEC note for guidance: good clinical practice for trials on medicinal products in the European community. Pharmacol Toxicol 1990;67:361-72. 27. Ehsanullah RSB, Page MC, Tildesley G, Wood JR. Prevention of gas- troduodenal damage induced by non-steroidal anti-inflammatory drugs: controlled trial of ranitidine. BMJ 1988;297:1017-21

28. Robinson MG, Griffin JW Jr, Bowers J, et al. Effect of ranitidine on gastroduodenal mucosal damage induced by nonsteroidal antiinflammatory drugs. Dig Dis Sci 1989;34:424-8.

29. Cullen DJE, Hawkey GM, Humphries H, et al. Role of non-steroidal anti-inflammatory drugs and Helicobacter pylori in bleeding peptic ulcer. Gastroenterology 1994;106:Suppl:A66. abstract.

30. Cullen DJE, Hawkey GM, Greenwood DC, et al. Peptic ulcer bleeding in the elderly: relative roles of Helicobacter pylori and non-steroidal antiinflammatory drugs. Gut 1997:41:459-62.

31. Hudson N, Balsitis M, Filipowicz F, Hawkey CJ. Effect of Helicobacter pylori colonisation on gastric mucosal eicosanoid synthesis in patients tak ing non-steroidal anti-inflammatory drugs. Gut 1993;34:748-51.

32. Hunt SM, McKenna SP, Williams J. Reliability of a population survey tool for measuring perceived health problems: a study of patients with osteoarthrosis. J Epidemiol Community Health 1981;35:297-300.

33. Dupuy HJ. The Psychological General Well-Being (PGWB) Index. In: Wenger NK, Mattson ME, Furberg CD, Elinson J. Assessment of quality of life in clinical trials of cardiovascular therapies. New York: Le Jacq Publishing, 1984:170-83.

34. Dimenäs E, Glise H, Hallerbäck B, Hernqvist H, Svedlund J, Wiklund I. Well-being and gastrointestinal symptoms among patients referred to en doscopy owing to suspected duodenal ulcer. Scand J Gastroenterol 1995; 30:1046-52

35. Ekström P, Carling L, Wetterhus S, et al. Prevention of peptic ulcer and dyspeptic symptoms with omeprazole in patients receiving continuous non-steroidal anti-inflammatory drug therapy: a Nordic multicentre study. Scand J Gastroenterol 1996;31:753-8.

36. Cullen D, Bardhan KD, Eisner M, et al. Primary gastroduodenal pro phylaxis with omeprazole for NSAID users. Aliment Pharmacol Ther (in press).

37. Bardhan KD, Bjarnason I, Scott DL, et al. The prevention and healing of acute non-steroidal anti-inflammatory drug-associated gastroduodenal mucosal damage by misoprostol. Br J Rheumatol 1993;32:990-5.

38. Garcia Rodriguez LA, Jick H. Risk of upper gastrointestinal bleeding and perforation associated with individual non-steroidal anti-inflammatory drugs. Lancet 1994;343:769-72.

39. Labenz J, Tillenburg B, Peitz U, et al. Efficacy of omeprazole one year after cure of Helicobacter pylori infection in duodenal ulcer patients. Am J Gastroenterol 1997;92:576-81

40. Verdú EF, Armstrong D, Idström J-P, et al. Effect of curing Helicobacter pylori infection on intragastric $\mathrm{pH}$ during treatment with omeprazole. Gut 1995;37:743-8.

41. Graham DY. Nonsteroidal anti-inflammatory drugs, Helicobacter pylori, and ulcers: where we stand. Am J Gastroenterol 1996;91:2080-6.

42. Jensen DM, Cheng S, Kovacs TOG, et al. A controlled study of ranitidine for the prevention of recurrent hemorrhage from duodenal ulcer. N Engl J Med 1994;330:382-6.

43. Penston JG, Wormsley KG. Nine years of maintenance treatment with ranitidine for patients with duodenal ulcer disease. Aliment Pharmacol Ther 1992;6:629-45.

44. Shallcross TM, Heatley RV. Effect of non-steroidal anti-inflammatory drugs on dyspeptic symptoms. BMJ 1990;300:368-9. 